\title{
Women's preferences for selective estrogen reuptake modulators: an investigation using the time trade-off technique
}

\author{
Angelique F Ralph ${ }^{1 *}$, Brittany Ager ${ }^{1}$, Melanie L Bell ${ }^{1,2,3}$, lan M Collins ${ }^{4}$, Lesley Andrews ${ }^{6}$, Kathy Tucker ${ }^{6}$,
} Nicole O'Reilly ${ }^{7}$, Kelly-Anne Phillips ${ }^{5}$ and Phyllis Butow ${ }^{1,2,8}$

\begin{abstract}
Purpose: Selective Estrogen Receptor Modulators (SERMs) reduce the risk of breast cancer for women at increased risk by 38\%. However, uptake is extremely low and the reasons for this are not completely understood. The aims of this study were to utilize time trade-off methods to determine the degree of risk reduction required to make taking SERMs worthwhile to women, and the factors associated with requiring greater risk reduction to take SERMs.

Methods: Women at increased risk of breast cancer $(N=107)$ were recruited from two familial cancer clinics in Australia. Participants completed a questionnaire either online or in pen and paper format. Hierarchical multiple linear regression analysis was used to analyze the data.

Results: Overall, there was considerable heterogeneity in the degree of risk reduction required to make taking SERMs worthwhile. Women with higher perceived breast cancer risk and those with stronger intentions to undergo (or who had undergone) an oophorectomy required a smaller degree of risk reduction to consider taking SERMs worthwhile.

Conclusion: Women at increased familial risk appear motivated to consider SERMs for prevention. A tailored approach to communicating about medical prevention is essential. Health professionals could usefully highlight the absolute (rather than relative) probability of side effects and take into account an individual's perceived (rather than objective) risk of breast cancer.
\end{abstract}

Keywords: Breast cancer; Chemoprevention; SERMs; Patient preferences; BRCA1

\section{Introduction}

A strong family history of breast cancer and/or carrying a germline mutation in the $B R C A 1$ or $B R C A 2$ gene, substantially increases breast cancer risk (Antoniou et al. 2003; Pharoah et al. 1997). For example, mutation carriers have average lifetime risks of $65 \%$ and $45 \%$ respectively (Antoniou et al. 2003), compared with 12\% for the Australian general population (Australian Institute of Health and Welfare 2009).

Risk reduction strategies for women with an elevated risk of breast cancer include surgery, namely bilateral mastectomy and bilateral pre-menopausal salpingo-oophorectomy,

\footnotetext{
* Correspondence: angelique.ralph@sydney.edu.au

'School of Psychology, University of Sydney, Sydney, New South Wales 2006, Australia

Full list of author information is available at the end of the article
}

and medication such as selective estrogen receptor modulators (SERMs) (Rebbeck et al. 2009; Rebbeck et al. 2004). There is strong evidence that SERMs such as tamoxifen and raloxifene, taken daily for 5 years, reduce breast cancer risk by $38 \%$ (Cuzick et al. 2013). However, uptake of these agents is very low, even in women at high familialrisk (Phillips et al. 2006; Savage 2007; Vogel 2010; Keogh et al. 2009; Evans et al. 2001; Collins et al. 2013). Whilst it has been estimated that $15 \%$ of women in the United States aged 35 to 79 could potentially benefit from tamoxifen (Freedman et al. 2003), less than $0.2 \%$ of women in this age range are taking tamoxifen (Waters et al. 2010).

The reasons for low SERM uptake are not completely understood, although fear of side effects, difficulty comprehending risk and biases against taking medication, have been shown to be important in several studies (Day et al. 
1999; Port et al. 2001; Lovegrove et al. 2000). Understanding how women make decisions about breast cancer risk management might ultimately enhance uptake. The Time Trade-Off (TTO) method, establishes willingness to trade-off quality of life for length of life and has been widely utilized to elicit patients' preferences in situations that involve complex trade-offs between the benefits and harms of medical decisions (De Haes \& Stiggelbout 1996; Duric et al. 2007; Lin et al. 2012; Simes \& Coates 2001). Studies investigating patient-preferences for adjuvantchemotherapy in early breast cancer have found that a surprising number of women judged negligible benefits $(0.1 \%$ to $1 \%$ increase in survival rate) sufficient to make adjuvant-chemotherapy worthwhile (Duric et al. 2007; Simes \& Coates 2001). Parenting concerns, minimizing future regret, doubts about information provided by healthcare professionals and feeling they had no choice were the main explanations given by women for judging negligible benefits worthwhile.

The present study aimed to expand on previous research by exploring not only the minimum absolute riskreduction that women judge necessary to make initiating SERMs worthwhile, but also the clinical and demographic variables associated with this outcome. Based on the literature, we hypothesized that higher objective breast cancer risk, younger age, being a parent and considering risk-reducing surgery would all be associated with requirement of a lower risk reduction to make taking SERMs worthwhile (Lovegrove et al. 2000; Tchou et al. 2004; Jansen et al. 2004).

\section{Methods}

\section{Participants}

Eligibility criteria included: being at moderate or high risk of breast cancer (see below), competency in English, aged 18 to 70 years, and no personal history of breast or ovarian cancer or bilateral mastectomy. Participants who had previously undergone bilateral oophorectomy (which reduces breast cancer risk if done while pre-menopausal) were not excluded, as their residual risk is still high enough to warrant consideration of SERMs.

\section{Procedure}

Consecutive eligible women identified from the clinic databases of two Australian Familial Cancer Clinics (FCCs) were invited to participate by the FCC; interested women were phoned by a researcher to gain verbal consent. Consenting women completed the study online or by paper and pencil. They first completed the consent form, then read a fact sheet that provided information on SERMs, risk-reducing mastectomy and salpingo-oophorectomy to ensure a basic level of knowledge, and then completed the questionnaire. Women were categorized as at moderate or high risk of breast cancer based on family history and BRCA1 and BRCA2 mutation status, using Cancer Australia definitions, that is, high risk is greater than three times the population risk and moderate risk is one and a half to three times population risk (NBOCC 2009). Ethics approval for the study was obtained from the University of Sydney and participating sites.

\section{Measures \\ Demographic characteristics}

We collected age, ethnicity, relationship status, parity, number of daughters, plans for future children, menopausal status, BRCA1 BRCA2 mutation status, cigarette smoking status, personal history of blood clots, and family and/or personal history of bilateral mastectomy and/or oophorectomy and/or SERM use.

\section{Intention to take SERMs: patient preferences}

The primary outcome, patient preferences, was assessed using the TTO method adapted from (Simes \& Coates 2001). Women were presented with hypothetical scenarios and asked to decide between taking and not taking SERMs. Women indicated if they would or would not take SERMs if taking SERMs were to reduce their lifetime breast cancer risk from a starting risk of $50 \%$ down to $50 \%$ (that is, not reduce their risk at all), then down to $49.5 \%$, to $49 \%$, to $48 \%$, to $45 \%$ and so-on down to $0 \%$ by $5 \%$ increments. A second scenario was presented from a starting risk of $20 \%$, with SERMs hypothetically reducing risk down to $20 \%$ (not reducing risk at all) then down to $19.5 \%$, to $19 \%$, to $18 \%$, to $17 \%$, to $15 \%$ and so-on down to $0 \%$ by increments alternating between 2 and $3 \%$.

These two scenarios were based on the average lifetime risk of developing breast cancer for a woman at high risk (50\%) and for a woman at moderate risk (20\%). The "tipping-point", the risk reduction required to make taking SERMs worthwhile, was computed for each participant for both the $50 \%$ and $20 \%$ risk scenarios by subtracting the percentage where the woman crossed from not taking SERMs to taking SERMs from the corresponding baseline risk. Thus, a lower tipping point represents a lower degree of risk reduction required to intend to take SERMs.

It was emphasized to participants that the choices were hypothetical; there were no right or wrong answers; and the numbers were hypothetical scenarios and did not apply to them personally. Following the TTO, women were asked to list, in order of importance, the three most important factors influencing their decision to take or not take SERMs.

\section{Data analysis}

Associations between TTO tipping points scores and clinical and demographic characteristics were explored through correlations and adjusted-analysis using multiple linear 
regression. In order to represent the equally important views of women who did not 'tip' (i.e., women who consistently chose to either take or not take SERMs, regardless of degree of benefit), 0.5 was added to all tipping point scores. Age and risk status were included as covariates in all multiple linear regressions due to strong theoretical rationale (Lovegrove et al. 2000; Tchou et al. 2004). Intention to have bilateral mastectomy and intention to have (or having had) bilateral oophorectomy were also included as binary covariates, as women do not consider SERMs in isolation but rather as an addition or alternative to other risk reduction strategies (Metcalfe et al. 2007). As history of blood clots and smoking status were not correlated with any of the outcomes, they were not included as covariates. Having a daughter/s was also omitted as a covariate as it demonstrated a large and significant correlation of $r=.70(p<.001)$ with another independent variable, parity.

Items women had listed as important in their decisionmaking during the TTO were thematically analyzed. For each woman, items were weighted from 3 to 1 from highest to least important, and categorized into identified themes. A weighted-frequency score was then calculated for each theme by summing the weightings of each item in the theme.

As some women in the sample had previously taken SERMs, a sensitivity-analysis was conducted to assess the impact this variable had on each of the models.

\section{Results}

\section{Sample}

Of the 407 invitations sent, 117 women responded and 107 (26\%) completed the questionnaire. Analysis comparing de-identified data on non-responders with that of responders indicated that more women at moderate risk participated (53\%) than did not participate (47\%) compared to women at high risk (33\% versus $67 \%$ ) or those who were BRCA1 or BRCA2 positive (24\% versus $76 \%$ ). However as few eligible moderate risk women were identified, the absolute numbers were small. There were no other differences identified between responders and nonresponders.

Participant characteristics are summarized in Table 1. The mean age was $43(S D=10.8)$. Forty-one women $(38 \%$ of the sample) were $B R C A 1$ or $B R C A 2$ mutation positive, $56(52 \%)$ were at high risk but without a documented mutation and $10(9 \%)$ were at moderate risk.

\section{Tipping points}

Tipping points are summarized in Figures 1 and 2. Some women had no tipping point. Specifically, $5.4 \%$ and $9.2 \%$ of women for the $50 \%$ and $20 \%$ baseline scenarios respectively, invariably chose to take SERMs and $7.5 \%$ and $15.3 \%$ of women for the $50 \%$ and $20 \%$ baseline scenarios respectively consistently chose not to take SERMs. There were no significant differences in the mean tipping points between risk groups (i.e., moderate, high, mutation positive) in either the 50\%-baseline risk scenario, $F(2,90)=$ $2.48, p=.09$, or the $20 \%$-baseline risk scenario, $F(2,95)=$ $1.63, p=.20$.

Sensitivity analysis showed that having previously taken SERMs did not appreciably change multivariate analysis results, therefore the results shown here include the whole sample. As shown in Table 2, perceived risk and intention to undergo, or has undergone oophorectomy accounted for a significant amount of variance in tipping point scores in both scenarios $\left(R^{2}=.19, p=.01\right.$, $R^{2}=.17, p=.02$ respectively). Women who intended to undergo or had undergone oophorectomy judged smaller amounts of risk reduction sufficient to take SERMs in both the $50 \%$ and $20 \%$ base risk scenarios. Additionally, women with higher perceived breast cancer risk required a smaller degree of risk reduction for it to be worthwhile for them to take SERMs in the $20 \%$ scenario.

\section{Qualitative responses}

Issues affecting their decision, listed by women, are summarized in Table 3. The risk reduction offered by SERMs, and one's personal level of risk and family concerns, were the most cited reasons for hypothetically choosing to take SERMs. Side effects was clearly the most cited reason for not taking SERMs, followed by low perceived efficacy of SERMs and choosing other methods of risk reduction. Most women $(n=53)$ did not specify which of the possible side effects were influencing their decision, however, of those who did, menopausal symptoms was the most frequently reported $(n=10)$, followed by unknown long-term consequences $(n=6)$, sexual function $(n=4)$, fertility $(n=4)$, weight gain $(n=2)$, osteoporosis $(n=3)$ and cognition $(n=1)$.

\section{Discussion and conclusion \\ Discussion}

This study is the first to our knowledge to apply the Time Trade-Off (TTO) method to elucidate how women at increased risk of breast cancer make decisions regarding using SERMs to reduce risk. The substantial minority of women who had no tipping-point was surprising. Six percent and $16 \%$ of women, for the $50 \%$ and $20 \%$ baseline scenarios respectively, consistently chose to take SERMs even when there would not be any reduction in the risk of breast cancer. These women reported being most influenced by: minimizing the stress and worry associated with being at increased risk; family concerns; and lowering their risk of breast cancer. Previous research has found that many women judge negligible benefits sufficient to engage in treatment for breast cancer (Duric et al. 2007; Simes \& Coates 2001; Heisey et al. 
Table 1 Demographic and clinical characteristics of participants at moderate risk of breast cancer, high risk of breast cancer and those with a mutation in the BRCA1 or BRCA2 gene

\begin{tabular}{|c|c|c|c|c|c|c|c|c|}
\hline \multirow[t]{3}{*}{ Variable } & \multirow{2}{*}{\multicolumn{2}{|c|}{$\begin{array}{c}\text { Moderate risk } \\
n=10\end{array}$}} & \multirow{2}{*}{\multicolumn{2}{|c|}{$\begin{array}{c}\text { High risk } \\
n=56\end{array}$}} & \multirow{2}{*}{\multicolumn{2}{|c|}{$\begin{array}{c}\text { Mutation positive } \\
\qquad n=41\end{array}$}} & \multirow{2}{*}{\multicolumn{2}{|c|}{$\begin{array}{c}\text { Combined } \\
N=107\end{array}$}} \\
\hline & & & & & & & & \\
\hline & $M$ & $S D$ & $M$ & $S D$ & $M$ & $S D$ & $M$ & $S D$ \\
\hline \multirow[t]{2}{*}{ Age (years) } & 41.8 & 10.2 & 44.5 & 11.0 & 41.2 & 10.7 & 43.0 & 10. \\
\hline & $n$ & $\%$ & $\mathrm{n}$ & $\%$ & $\mathrm{n}$ & $\%$ & $\mathrm{n}$ & $\%$ \\
\hline \multicolumn{9}{|l|}{ Ethnicity } \\
\hline Australian & 4 & 40 & 45 & 80 & 30 & 73 & 79 & 74 \\
\hline European & 3 & 30 & 6 & 11 & 4 & 10 & 13 & 12 \\
\hline Asian & 0 & 0 & 2 & 4 & 2 & 5 & 4 & 4 \\
\hline Other & 3 & 30 & 3 & 5 & 5 & 12 & 11 & 10 \\
\hline
\end{tabular}

Relationship status

Single

Married/de facto

Children

Yes

No

Daughter/s

Yes

No

Want future children

Yes

No

Unsure

Menopausal status

Premenopausal

Perimenopausal

Menopausal

Unsure

Family history of prophylactic mastectomy

Yes

No

Family history of prophylactic oophorectomy

$$
\text { Yes }
$$

No

Family history of SERMs

$$
\text { Yes }
$$

No

Personal history of oophorectomy

Yes

No

Personal history of SERMs

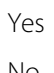

No

10

\section{6}

40

9

90

$5 \quad 50$

5

50

11

45

20

80

60

19

34

21

20

14

27

\section{4}

66

16

25

39

$$
61
$$

61

$\begin{array}{ll}32 & 30 \\ 75 & 70\end{array}$

6

$$
40
$$

$10 \quad 18$

8

8
28

51

$\begin{array}{ll}61 & 57 \\ 45 & 42\end{array}$

49

42

$\begin{array}{ll}4 & 40 \\ 4 & 40\end{array}$

$\begin{array}{lll}20 & 22 & 21 \\ 68 & 72 & 67 \\ 12 & 12 & 11\end{array}$

$31 \quad 55$

19

10

$1 \quad 10$

6

11

0

1

10

$\begin{array}{ll}15 & 27 \\ 4 & 7\end{array}$

20

30

3
7

$3 \quad 30$

$\begin{array}{ll}14 & 25 \\ 42 & 75\end{array}$

70

$1 \quad 10$

$\begin{array}{ll}10 & 18 \\ 46 & 82\end{array}$

2

$\begin{array}{ccc}12 & 12 & 11 \\ 46 & 57 & 53 \\ 0 & 7 & 7 \\ 49 & 36 & 34 \\ 5 & 7 & 7\end{array}$


Table 1 Demographic and clinical characteristics of participants at moderate risk of breast cancer, high risk of breast cancer and those with a mutation in the BRCA1 or BRCA2 gene (Continued)

\begin{tabular}{lccccccc}
\hline Cigarettes per day & & & & & & \\
None & 8 & 80 & 53 & 95 & 40 & 98 & 0 \\
10 or less & 2 & 20 & 3 & 5 & 0 & 5 & 5 \\
11 to 20 & 0 & 0 & 0 & 0 & 1 & 1 & 1 \\
$\begin{array}{l}\text { History of blood clots } \\
\text { Yes }\end{array}$ & 1 & 10 & 0 & 0 & 0 & 0 & 1 \\
No & 9 & 90 & 56 & 100 & 41 & 100 & 106 \\
\hline
\end{tabular}

2006). For example, Duric and colleagues found that 52$61 \%$ of women with early stage breast cancer judged one extra day in a life expectancy of 5-years sufficient to have adjuvant chemotherapy, regardless of the baseline risk, of breast cancer related death (Duric et al. 2007).

Further, many women would consider SERMs if the benefits were sufficiently large, with $70 \%$ of moderate and $90 \%$ of high risk women respectively willing to consider SERMs for a $40 \%$ or less risk reduction (likely realistic). Thus general interest in SERMs in this group of moderate and high risk women was high.

A small proportion of women consistently chose not to take SERMs, even if SERMs reduced their risk of breast cancer to zero. All such women listed side effects as one of the top three important factors influencing their decision. This is congruent with previous research (Port et al.
2001; Lovegrove et al. 2000; Bober et al. 2004) demonstrating that women often decline to take tamoxifen because of fear of side effects which are frequently overestimated. Future research should explore which side effects are most concerning to women. Perhaps women could be offered a trial of SERMs to determine if they are substantially affected by vasomotor and gynecologic side effects, before making a decision whether to plan for 5 years of use. Communicating absolute, rather than relative risks for serious potential side effects such as endometrial cancer and thrombosis may also help to put these into perspective, especially for pre-menopausal women where they are rare (Keogh et al. 2009; Harvey et al. 2011; Fisher et al. 1998).

Unlike low benefits required by most women with breast cancer to take adjuvant chemotherapy (Duric et al. 2007), many women in the current study required a large risk

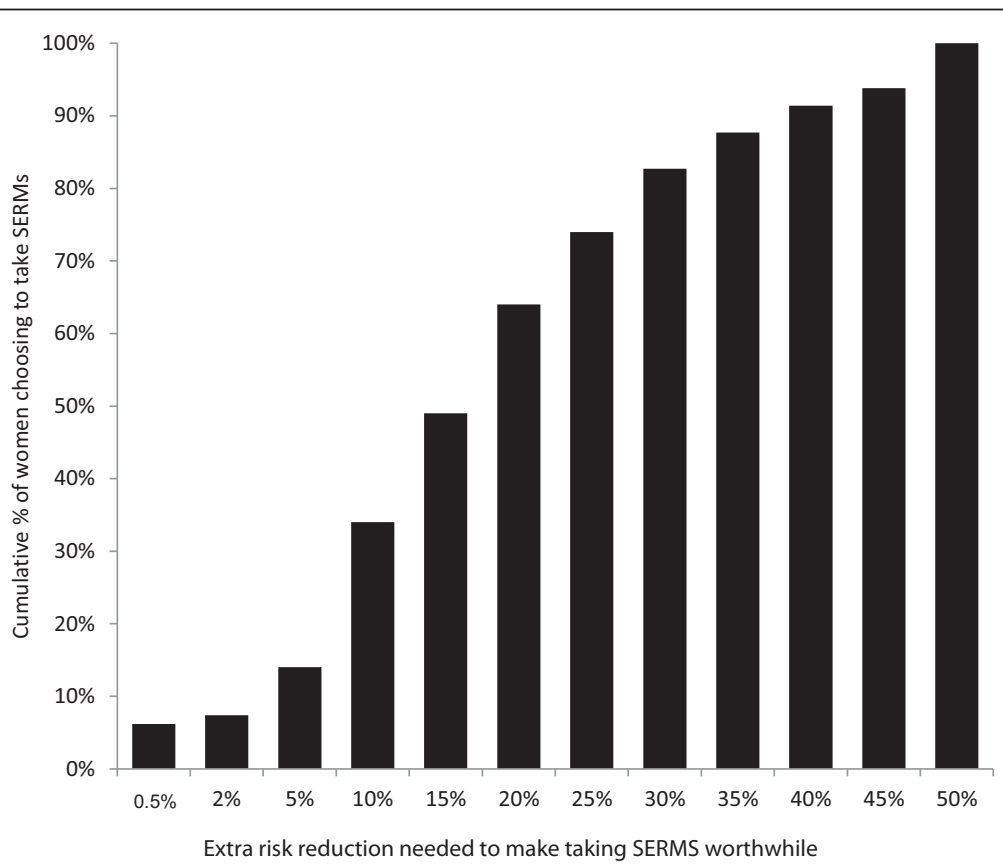

Figure 1 Amongst women who did 'tip' ( $n=81$ ), cumulative proportions of women considering taking SERMs for various degrees of risk reduction for $\mathbf{5 0} \%$ baseline scenario. Twelve participants were excluded from the analysis of the 50\%-baseline scenario as they switched multiple times between taking SERMs and not taking SERMs throughout the same baseline scenario; thus a tipping point could not be calculated. 


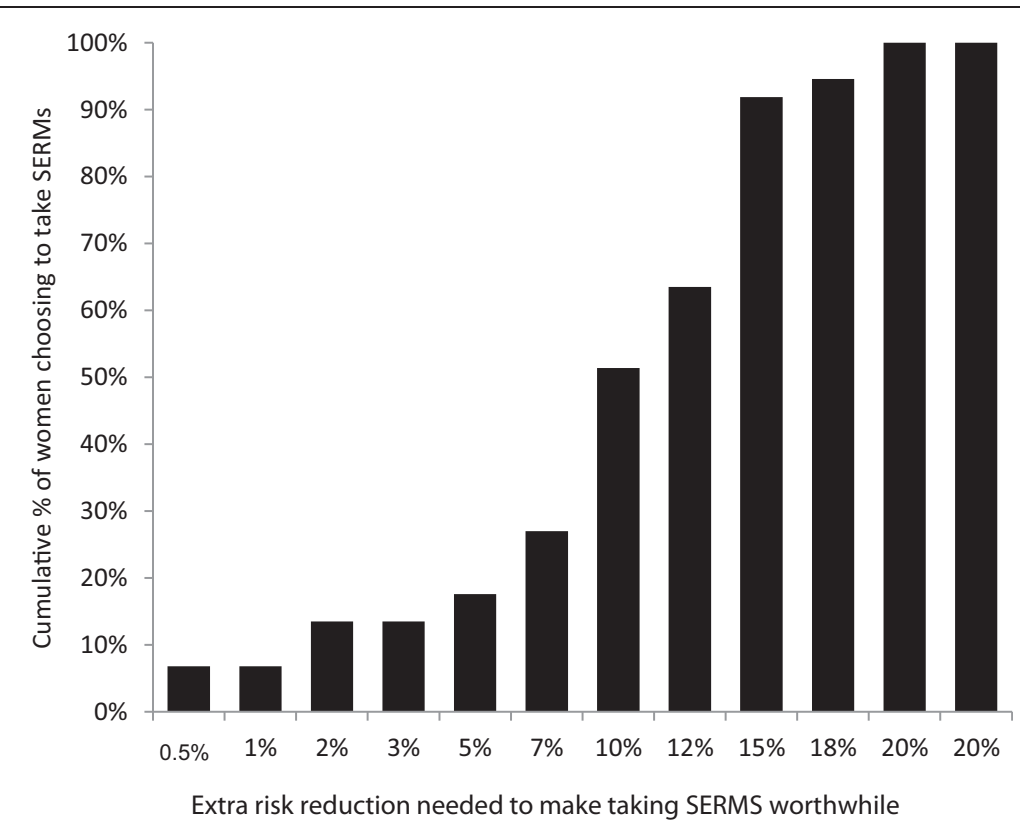

Figure 2 Amongst women who did 'tip' ( $n=74)$, cumulative proportions of women considering taking SERMs for various degrees of risk reduction for $\mathbf{2 0} \%$ baseline scenario. Eight participants were excluded from the analysis of the $20 \%$-baseline scenario as they switched multiple times between taking SERMs and not taking SERMs throughout the same baseline scenario; thus a tipping point could not be calculated.

Table 2 Multiple linear regression analysis predicting tipping point at $50 \%$ and $20 \%$ baseline risk

\begin{tabular}{|c|c|c|c|}
\hline Dependent variable & $\begin{array}{l}\text { Independent } \\
\text { variables }\end{array}$ & B (95\% Cl) & P-value \\
\hline \multirow{10}{*}{$\begin{array}{l}\text { Tipping point at } \\
50 \% \text { baseline risk }\end{array}$} & $\left(R^{2}=.19\right)$ & & .01 \\
\hline & Age & $.05(-.3,4)$ & .77 \\
\hline & Risk status & & \\
\hline & Moderate & Reference & \\
\hline & High & $-6.9(-18.3,4.5)$ & .23 \\
\hline & Mutation positive & $-1.5(-13.8,4.5)$ & .81 \\
\hline & Has children & $-2.7(-10.1,4.8)$ & .48 \\
\hline & $\begin{array}{l}\text { Intention to have } \\
\text { mastectomy }\end{array}$ & $-4.2(-11.0,2.6)$ & .22 \\
\hline & $\begin{array}{l}\text { Intention to have } \\
\text { oophorectomy }\end{array}$ & $-11.7(-18.5,-4.8)$ & .001 \\
\hline & Perceived risk & $-0.1(-.15, .13)$ & .87 \\
\hline \multirow{10}{*}{$\begin{array}{l}\text { Tipping point at } \\
20 \% \text { baseline risk }\end{array}$} & $\left(R^{2}=.17\right)$ & & .02 \\
\hline & Age & $.03(-.1, .2)$ & .72 \\
\hline & Risk status & & \\
\hline & Moderate & Reference & \\
\hline & High & $-1.5(-.6 .4,3.4)$ & .54 \\
\hline & Mutation positive & $-.1(-5.4,5.2)$ & .96 \\
\hline & Has children & $-.5(-3.7,2.7)$ & .76 \\
\hline & $\begin{array}{l}\text { Intention to have } \\
\text { mastectomy }\end{array}$ & $-.9(-3.9,2.0)$ & .54 \\
\hline & $\begin{array}{l}\text { Intention to have } \\
\text { oophorectomy }\end{array}$ & $-3.7(-6.7,-.8)$ & .02 \\
\hline & Perceived risk & $-.1(-.1, .0)$ & .01 \\
\hline
\end{tabular}

Regression coefficients B and 95\% confidence intervals $(\mathrm{Cl})$ are shown.
Table 3 Categories of factors women considered most influential in their hypothetical decision to take or not take SERMs

\begin{tabular}{|c|c|c|}
\hline Category & & Weighted frequency ${ }^{\mathrm{a}}$ \\
\hline \multicolumn{3}{|l|}{ Incentives } \\
\hline & Risk reduction & 96 \\
\hline & Personal risk & 52 \\
\hline & Reduce stress and worry & 17 \\
\hline & Family concerns & 25 \\
\hline & Age & 2 \\
\hline & Side effects ${ }^{b}$ & 2 \\
\hline \multicolumn{3}{|l|}{ Barriers } \\
\hline & Side effects & 214 \\
\hline & Other risk reduction methods & 46 \\
\hline & Inadequate efficacy & 140 \\
\hline & Taking medication & 29 \\
\hline & Age & 15 \\
\hline & Lack of information & 10 \\
\hline & Medical advice & 18 \\
\hline & Cost & 14 \\
\hline
\end{tabular}

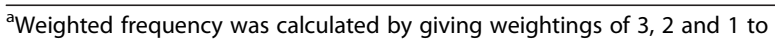
answers listed as of highest importance, of next degree of importance and of least importance respectively. ${ }^{b}$ Positive side effects were listed. 
reduction before choosing to take SERMs. In the 20\% base risk scenario, over $40 \%$ of women needed the risk to be halved to $10 \%$ in order to consider taking SERMs to be worthwhile. Previous studies have reported that healthy individuals with no current symptoms have a lower tolerance for potential toxicities. Therefore, women 'at risk' rather than ill may require greater potential benefit from SERMs to outweigh the associated negative aspects and increase the likelihood of choosing this risk reduction option (Lawrence et al. 2012).

Younger age, higher objective risk and having children produced results in the predicted direction, however, none were significantly associated with degree of risk reduction required to take SERMs, for either the $20 \%$ or the $50 \%$ baseline risk scenario. Previous studies have had conflicting findings regarding the association between age and acceptance of risk-reducing tamoxifen (Lovegrove et al. 2000; Tchou et al. 2004; Bober et al. 2004; Meiser et al. 2003). Whilst some women may decline SERMs to avoid premature menopausal symptoms, other women may be more influenced by the fact that the most favorable risk benefit ratio is seen in premenopausal women (Harvey et al. 2011).

Women who reported that they were likely to undergo (or had undergone) an oophorectomy required less risk reduction in order to choose to take SERMs than women who were not considering this procedure. It is perhaps not surprising that women who are motivated enough to consider surgical risk reduction may be more willing to accept SERMs.

Subjective but not objective breast cancer risk was predictive of the degree of risk reduction required to take SERMs in the $20 \%$ baseline condition, with neither predictive in the $50 \%$ baseline condition. This is congruent with previous studies where subjective but not objective risk was associated with either considering tamoxifen (Meiser et al. 2003) or uptake of tamoxifen (Tchou et al. 2004; Bober et al. 2004). It is a well documented phenomenon that women overestimate their risk of breast cancer e.g. (Lovegrove et al. 2000; Heisey et al. 2006; Black et al. 1995; Davis et al. 2004; Lerman et al. 1995) and that perception of risk is rarely a direct comprehension of accurately understood probability information (Bober et al. 2004; Hopwood 2000). Thus care must be taken in discussing risk with these women, as it will influence their decision-making.

The present study has a number of limitations. It was cross-sectional and hypothetical, thus causation cannot be implied and it is not known whether intention to take SERMs would translate into actual behavior. Furthermore, women are unlikely to consider SERMs in isolation but rather as an addition or alternative to other methods of risk reduction such as bilateral mastectomy and/or oophorectomy. However, it was not feasible in the current study to examine women's preferences for multiple methods of risk reduction.

The study had a relatively low response rate of $26 \%$, although data on non-responders suggests this did not result in a biased sample. Nevertheless, the relatively high prevalence of previous SERM use in this sample, compared with expected rates, (Collins et al. 2013) suggests that the sample could have been unusual, thus results should be generally applied with some caution. Women who attend Australian familial cancer clinics have aboveaverage educational and socioeconomic levels and may not be representative of the broader population of women at increased risk (Meiser et al. 2000; Coyne \& Anderson 1999; Coyne et al. 2000; Cull et al. 1998). Nonetheless, findings are highly relevant to countries such as Australia, where the vast majority of assessment and genetic-testing of women at increased familial risk is done by a network of Family Cancer Centers, and these women are the most likely to be offered SERMs (Keogh et al. 2009).

\section{Practice implications and future research}

Many women at increased risk of breast cancer are interested in using SERMs to reduce their risk. Health professionals could focus on informing women about the proven long-term benefits of SERMs and the high quality of the underpinning evidence. As side effects represent a highly salient factor to women, and are often overestimated, the absolute (rather than relative) probability of side effects should be highlighted. Our study shows that individual preferences vary widely and thus a tailored approach to medical prevention is essential, perhaps with the assistance of a computerized decision aid that can effectively translate reported relative benefits and risks into absolute benefits and risks individualized to each woman's circumstances.

Future research should endeavor to assess women's preferences for SERMs in the context of other riskreduction methods and/or in a sample of women who have declined surgical risk reduction procedures.

\section{Ethical standards}

This study was carried out according to national legislation and was approved by the Human Research Ethics Committee (12/020 [HREC/12/POWH/42]).

Competing interest

The authors declare that they have no competing interest.

Authors' contribution

$P B, A R, B A, M L B, K A P, K T$ and $L A$ contributed to the design and protocol of the study. KAP, IMC, KT and LA recruited participants. AFR and BA and collected and analysed the data. MLB and NO assisted in the statistical analysis of the data. AFR and PB drafted the manuscript which was also revised by KAP, MLB and IMC. All authors read and approved the final manuscript. 


\section{Acknowledgements}

We thank the study participants and the clinical and administrative staff of the Peter MacCallum Cancer Centre Family Cancer Clinic. KAP is a National Breast Cancer Foundation Practitioner Fellow.

\section{Author details}

${ }^{1}$ School of Psychology, University of Sydney, Sydney, New South Wales 2006, Australia. ${ }^{2}$ Psycho-Oncology Co-operative Research Group (PoCoG), University of Sydney, Sydney, New SouthWales 2006, Australia. ${ }^{3}$ Mel and Enid Zuckerman College of Public Health, University of Arizona, Tucson, Arizona 85724, USA. ${ }^{4}$ Division of Cancer Medicine, Peter MacCallum Cancer Centre, East Melbourne, Victoria 3002, Australia. ${ }^{5}$ Sir Peter MacCallum Dept. of Oncology, The University of Melbourne, Parkville, Victoria 3010, Australia. ${ }^{6}$ Hereditary Cancer Clinic, Prince of Wales Hospital, 147 Barker Street, Randwick, New South Wales 2031, Australia. ${ }^{7}$ School of Psychiatry, University of New South Wales, Randwick, New South Wales 2031, Australia. ${ }^{8}$ Centre for Medical Psychology and Evidence-based Decision-making (CeMPED), University of Sydney, Sydney, New South Wales 2006, Australia.

Received: 24 April 2014 Accepted: 2 May 2014

Published: 24 May 2014

\section{References}

Antoniou A, Pharoah PDP, Narod S, Risch HA, Eyfjord JE, Hopper JL, Loman N, Olsson H, Johannsson O, Borg Å, Pasini B, Radice P, Manoukian S, Eccles DM, Tang N, Olah E, Anton-Culver H, Warner E, Lubinski J, Gronwald J, Gorski B, Tulinius $H$, Thorlacius S, Eerola H, Nevanlinna H, Syrjäkoski K, Kallioniemi OP, Thompson D, Evans C, Peto J, Lalloo F, Evans DG, Easton DF (2003) Average risks of breast and ovarian cancer associated with BRCA1 or BRCA2 mutations detected in case series unselected for family history: a combined analysis of 22 studies. Am J Hum Genet 72(5):1117-1130, doi:10.1086/375033

Australian Institute of Health and Welfare (2009) Breast cancer in Australia: an overview, 2009 (Cancer series no. 50. Cat. no. CAN 46. Cancer series no. 50. Cat. no. CAN 46. AlHW, Canberra

Black WC, Nease RF, Tosteson ANA (1995) Perceptions of breast cancer risk and screening effectiveness in women younger than 50 years of age. J Natl Cancer Inst 87(10):720-731, doi:10.1093/jnci/87.10.720

Bober SL, Hoke LA, Duda RB, Regan MM, Tung NM (2004) Decision-making about tamoxifen in women at high risk for breast cancer: clinical and psychological factors. J Clin Oncol 22(24):4951-4957, doi:10.1200/jco.2004.05.192

Collins IM, Milne RL, Weideman P, McLachlan SA, Friedlander ML, KConFab Investigators, Hopper JL, Phillips KA (2013) Preventing breast and ovarian cancers in high-risk BRCA1 and BRCA2 mutation carriers. (kConFab). Med J Aust 199:680-683

Coyne JC, Anderson KK (1999) Marital status, marital satisfaction, and support processes among women at high risk for breast cancer. J Fam Psychol 13(4):629

Coyne JC, Benazon NR, Gaba CG, Calzone K, Weber BL (2000) Distress and psychiatric morbidity among women from high-risk breast and ovarian cancer families. J Consult Clin Psychol 68(5):864

Cull A, Miller H, Porterfield T, Mackay J, Anderson E, Steel C, Elton R (1998) The use of videotaped information in cancer genetic counselling: a randomized evaluation study. Br J Cancer 77(5):830

Cuzick J, Sestak I, Bonanni B, Costantino JP, Cummings S, DeCensi A, Dowsett M, Forbes JF, Ford L, LaCroix AZ, Mershon J, Mitlak BH, Powles T, Veronesi U, Vogel V, Wickerham DL (2013) Selective oestrogen receptor modulators in prevention of breast cancer: an updated meta-analysis of individual participant data. Lancet 381(9880):1827-1834, doi: http://dx.doi.org/10.1016/ S0140-6736(13)60140-3

Davis S, Stewart S, Bloom J (2004) Increasing the accuracy of perceived breast cancer risk: results from a randomized trial with Cancer Information Service callers. Prev Med 39(1):64-73, doi:10.1016/j.ypmed.2004.02.043

Day R, Ganz PA, Costantino JP, Cronin WM, Wickerham DL, Fisher B (1999) Health-related quality of life and tamoxifen in breast cancer prevention: a report from the national surgical adjuvant breast and bowel project P-1 study. J Clin Oncol 17(9):2659

De Haes J, Stiggelbout A (1996) Assessment of values, utilities and preferences in cancer patients. Cancer Treat Rev 22:13-26, doi:10.1016/S0305-7372(96) 90059-6

Duric VM, Butow PN, Sharpe L, Boyle F, Beith J, Wilcken NRC, Heritier S, Coates AS, John Simes R, Stockler MR (2007) Psychosocial factors and patients' preferences for adjuvant chemotherapy in early breast cancer. Psychooncology 16(1):48-59, doi:10.1002/pon.1045

Evans DGR, Lalloo F, Shenton A, Boggis C, Howell A (2001) Uptake of screening and prevention in women at very high risk of breast cancer. Lancet 358 (9285):889-890, doi:10.1016/S0140-6736(01)06039-1

Fisher B, Costantino JP, Wickerham DL, Redmond CK, Kavanah M, Cronin WM, Vogel V, Robidoux A, Dimitrov N, Atkins J (1998) Tamoxifen for prevention of breast cancer: report of the national surgical adjuvant breast and bowel project P-1 study. J Natl Cancer Inst 90(18):1371-1388, doi:10.1093/jnci/ 90.18 .1371

Freedman AN, Graubard BI, Rao SR, McCaskill-Stevens W, Ballard-Barbash R, Gail $\mathrm{MH}$ (2003) Estimates of the number of US women who could benefit from tamoxifen. J Natl Cancer Inst 95(7):526-532

Harvey SL, Francis JE, McBride AJ, Bishop JF, Phillips KA (2011) Medication to prevent breast cancer-too much to swallow? Med J Aust 195(11-12):646-649, doi:10.5694/mja11.10830

Heisey R, Pimlott N, Clemons M, Cummings S, Drummond N (2006) Women's views on chemoprevention of breast cancer: qualitative study. Can Fam Physician 52(5):624-625

Hopwood P (2000) Breast cancer risk perception: what do we know and understand? Breast Cancer Res 2(6):387, doi:10.1186/bcr83

Jansen SJT, Otten W, Stiggelbout AM (2004) Review of determinants of patients' preferences for adjuvant therapy in cancer. J Clin Oncol 22(15):3181-3190, doi:10.1200/jco.2004.06.109

Keogh LA, Hopper JL, Rosenthal D, Phillips KA (2009) Australan clinicians and chemoprevention for women at high familial risk for breast cancer. Hered Cancer Clin Pract 7(9): doi:10.1186/1897-4287-7-9

Lawrence L, Narod S, Tuttle TM (2012) SERMs: underused and under the radar. Hem/Onc today 11(19):1-14

Lerman C, Lustbader E, Rimer B, Daly M, Miller S, Sands C, Balshem A (1995) Effects of individualized breast cancer risk counseling: a randomized trial. J Natl Cancer Inst 87(4):286-292, doi:10.1093/jnci/87.4.286

Lin M, Yu W, Wang S (2012) Examination of assumptions in using time tradeoff and standard gamble utilities in individuals with spinal cord injury. Arch Phys Med Rehabil 93(2):245-252, doi:10.1016/j.apmr.2011.08.039

Lovegrove E, Rumsey N, Harcourt D, Cawthorn S (2000) Factors implicated in the decision whether or not to join the tamoxifen trial in women at high familial risk of breast cancer. Psychooncology 9(3):193-202, doi:10.1002/1099-1611

Meiser B, Butow P, Friedlander M, Schnieden V, Gattas M, Kirk J, Suthers G, Haan E, Tucker K (2000) Intention to undergo prophylactic bilateral mastectomy in women at increased risk of developing hereditary breast cancer. J Clin Oncol 18(11):2250-2257

Meiser B, Butow P, Price M, Bennett B, Berry G, Tucker K (2003) Attitudes to prophylactic surgery and chemoprevention in Australian women at increased risk for breast cancer. J Womens Health 12(8):769-778

Metcalfe K, Poll A, O'connor A, Gershman S, Armel S, Finch A, Demsky R, Rosen B, Narod S (2007) Development and testing of a decision aid for breast cancer prevention for women with a BRCA1 or BRCA2 mutation. Clin Genet 72 (3):208-217, doi:10.1111/j.1399-0004.2007.00859.x

National Breast Ovarian Cancer Centre (2009) Breast cancer risk factors: a review of the evidence. Australian Government Department of Health and Ageing, Sydney

Pharoah PD, Day NE, Duffy S, Easton DF, Ponder BA (1997) Family history and the risk of breast cancer: a systematic review and meta-analysis. Int J Cancer 71 (5):800-809

Phillips KA, Jenkins MA, Lindeman GJ, McLachlan SA, McKinley JM, Weideman PC, Hopper JL, Friedlander ML, kConFab I (2006) Risk-reducing surgery, screening and chemoprevention practices of BRCA1 and BRCA2 mutation carriers: a prospective cohort study. Clin Genet 70(3):198-206, doi:10.1111/j.1399$0004.2006 .00665 x$

Port ER, Montgomery LL, Heerdt AS, Borgen PI (2001) Patient reluctance toward tamoxifen use for breast cancer primary prevention. Ann Surg Oncol 8(7):580-585

Rebbeck TR, Friebel T, Lynch HT, Neuhausen SL, van 't Veer L, Garber JE, Evans GR, Narod SA, Isaacs C, Matloff E, Daly MB, Olopade OI, Weber BL (2004) Bilateral prophylactic mastectomy reduces breast cancer risk in BRCA1 and BRCA2 mutation carriers: the PROSE study group. J Clin Oncol 22(6):1055-1062, doi:10.1200/jco.2004.04.188

Rebbeck TR, Kauff ND, Domchek SM (2009) Meta-analysis of risk reduction estimates associated with risk-reducing salpingo-oophorectomy in BRCA1 or BRCA2 mutation carriers. J Natl Cancer Inst 101(2):80-87, doi:10.1093/jnci/ $\operatorname{djn} 442$ 
Savage $L$ (2007) Researchers wonder why high-risk women are not taking chemoprevention drugs. J Natl Cancer Inst 99(12):913-914, doi:10.1093/jnci/ djm032

Simes RJ, Coates AS (2001) Patient preferences for adjuvant chemotherapy of early breast cancer: how much benefit is needed? J Natl Cancer Inst Monogr 2001(30):146-152, doi:10.1093/oxfordjournals.jncimonographs.a003453

Tchou J, Hou N, Rademaker A, Jordan VC, Morrow M (2004) Acceptance of tamoxifen chemoprevention by physicians and women at risk. Cancer 100 (9):1800-1806, doi:10.1002/cncr.20205

Vogel VG (2010) Tipping the balance for the primary prevention of breast cancer. J Natl Cancer Inst 102(22):1683-1685, doi:10.1093/jnci/djq435

Waters EA, Cronin KA, Graubard Bl, Han PK, Freedman AN (2010) Prevalence of tamoxifen use for breast cancer chemoprevention among US women. Cancer Epidemiol Biomarkers Prev 19(2):443-446

doi:10.1186/2193-1801-3-264

Cite this article as: Ralph et al.: Women's preferences for selective

estrogen reuptake modulators: an investigation using the time trade-off technique. SpringerPlus 2014 3:264.

\section{Submit your manuscript to a SpringerOpen ${ }^{\circ}$} journal and benefit from:

- Convenient online submission

- Rigorous peer review

- Immediate publication on acceptance

- Open access: articles freely available online

- High visibility within the field

- Retaining the copyright to your article

Submit your next manuscript at $>$ springeropen.com 